\title{
Engineered Warp Knit Auxetic Fabrics
}

\section{Samuel C. Ugbolue ${ }^{1 *}$, Yong K. Kim¹, Steven B. Warner ${ }^{2}$, Qinguo Fan'1, Chen-Lu Yang ${ }^{3}$, Olena Kyzymchuk ${ }^{4}$, Yani Feng' and John Lord}

${ }^{1}$ Department of Bioengineering, University of Massachusetts, Dartmouth, MA 02747, USA

${ }^{2}$ Department of Mechanical Engineering, University of Massachusetts, Dartmouth, MA 02747, USA

${ }^{3}$ Advanced Technology and Manufacturing Center, University of Massachusetts, Dartmouth MA 02747, USA

${ }^{4}$ Department of Knitting Technology, Kiev National University of Technologies and Design, Kyiv, Ukraine

\begin{abstract}
Auxetic textiles comprise a class of extraordinary materials that increase in size when stretched and are being considered in many applications of technical textiles. Sustained efforts to fabricate auxetic fabric structures are sparse and the use of auxetic materials has been limited because of problems with deploying them in their fabricated forms. Auxetic materials based on fibers and fabrics may be able to circumvent these and other limitations. Thus, the use of auxetic fibers in an engineered textile structure can be facilitated by the development of cost effective, productive processes in which large quantities of textile materials exhibit the very unusual, interesting and useful property of becoming wider when stretched and thinner when compressed. Such a process will revolutionize the technical textiles and protective clothing industry. Our thrust in this research is to combine our knowledge of geometry and fabric structural characteristics to engineer auxetic textiles and to determine the properties of such auxetic textile fabrics. Our efforts to produce auxetic knit structures from non-auxetic yarns are described in this paper.
\end{abstract}

Keywords: Auxetic; Negative Poisson's ratio; Warp knit; Technical textiles; Geometrical structural unit cell

\section{Introduction}

Auxetic textiles belong to a class of extraordinary materials which become thicker when stretched perpendicular to the applied force. In other words, auxetic materials have negative Poisson's ratio. Such materials are increasingly attaining some prominence in ongoing research of technical textiles [1]. A major production route could be, first, to synthesize the auxetic polymers and then to produce the yarn $[2,3]$ and knitted fabrics and thereafter, form composites from these polymers [4-7]. Efforts to fabricate auxetic fabric structures are limited. Several geometrical configurations have been proposed [5] but a few [8] has been engineered into functional auxetic textile structure. Our thrust in this research is to combine our knowledge of geometry and fabric structural characteristics to engineer auxetic textiles and to determine the properties of such auxetic textile fabrics. Our efforts to produce auxetic knit structures from non-auxetic yarns are described here.

\section{Auxetic textile filaments}

In 2006, Hook and Evans [9] adopted an alternative approach to the development of auxetic textile filaments. They produced a multifilament construction in which a high-stiffness filament is wrapped helically around a thicker low-stiffness filament. Neither of the constituting filaments is required to be auxetic. The overall multifilament construction exhibits auxetic behavior upon stretching due to straightening of the high-stiffness filament that causes the lower stiffness filament to helically wrap around it. This multifilament construction can be produced using existing textile machinery, such as wrap spinning, for instance. Recently, Hu et al. [8] have devoted attention to the development of auxetic fabrics using flat knitting technology.

\section{Properties of auxetic materials}

Researchers have studied the hardness properties of many of the synthetic auxetic materials produced to date, and enhancements have been found across the board in materials such as polymeric and metallic foams [10,11], carbon fiber composite laminates [12], and micro porous polymers $[13,14]$. Alderson et al. $[15,16]$ studied the hardness of polyethylene and Ultra High Molecular Weight Polyethylene (UHMWPE) with a negative Poisson's ratio and found that the presence of a negative Poisson's ratio resulted in enhancements of the hardness by up to a factor of 2 over conventional UHMWPE. Recent research results on auxetic fibers [17] suggest that annealing enhances the mechanical properties of these fibers and may provide a further route to enhancing auxeticity in improving homogeneity by over $40 \%$. A major problem with conventional materials is that they can hardly be curved into a doubly curved or domed shape; instead, the core forms a saddle shape on bending. However, in the case of auxetic material, double curvature can be easily achieved [18]. Finally, auxetic materials have the potential of being used as strain amplifiers, piezoelectric devices, and structural health monitoring components.

\section{Potential applications of auxetic materials}

Composite materials: It has been suggested [18] that an auxetic fiber within a composite would resist fiber pull-out. When an auxetic fiber is pulled, it will expand and effectively lock into the matrix rather than contracting and pulling out easily as a conventional fiber would do. Thus, auxetic materials can be used in a diverse range of applications, including as core materials in curved sandwich panel composite components, directional pass band filters, Micro-ElectroMechanical Systems (MEMS) devices, filters and sieves, seat cushion

*Corresponding author: Samuel C Ugbolue , Department of Bioengineering, University of Massachusetts, Dartmouth, MA 02747, USA, Tel:+1 5089998803 ; E-mail: sugbolue@gmail.com

Received January 06, 2012; Accepted January 09, 2012; Published January 11 2012

Citation: Ugbolue SC, Kim YK, Warner SB, Fan Q, Yang CL, et al. (2012) Engineered Warp KnitAuxetic Fabrics. J Textile Sci Engg 2:e103. doi:10.4172/2165 8064.1000e103

Copyright: (c) 2012 Ugbolue SC, et al. This is an open-access article distributed under the terms of the Creative Commons Attribution License, which permits unrestricted use, distribution, and reproduction in any medium, provided the original author and source are credited. 
material, energy absorption components, viscoelastic damping materials, and fastening devices. Auxetic composite laminates and composites containing auxetic constituents also provide enhancements in fracture toughness, and static and low velocity impact performance that aptly demonstrate potential in energy absorber components.

Medical applications: An example of a potential technical textile application is the 'smart bandage' [18]. It is capable of releasing a useful (anti-bacterial) agent from the pores of the filaments due to the high volume change associated with this unusual behavior. Auxetic fabrics can also be used in the healthcare industry for medical sutures and dental floss.

Protective end-uses and armor: Auxetic fabrics will be invaluable for personal protective fabrications and flexible armors, adaptive and deployable structures, energy absorption components, viscoelastic damping materials, packaging, car headrests, and bumper systems, in aerospace and construction industry, in such applications as biomedical filtration materials, snap-like fasteners, climbing ropes and in upholstery.

\section{Design Concept}

The model depicted in Figure 1 has been shown to be successful for explaining the auxetic behavior of some engineering foams [5]. Many models of deformation within network materials proposed by Gaspar et al. [12] make use of the assumption that there is a single mode of deformation that dominates over other modes. Some of these network models [13] have been put forward to resemble materials that may exhibit a negative Poisson's ratio but have yet to be manufactured. The broken-rib model by Smith et al. [5] is one such model. The results by Gaspar et al. [12] showed that a material with this microstructure does produce a negative Poisson's ratio. Our task has been to translate the concepts in the models in order to produce functional textile structures $[19,20]$.

It is known that textiles with net structures are the more preferred materials and geometry for composites. Warp knitting technology provides the most suitable knowhow for net structures. During warp knitting large numbers of yarns are simultaneously fed into the machine. The major advantages of warp knitting are its versatility and its high production speed. The set-up costs are, however, considerable since the knitting machine has to be equipped with one or two needle beds and many guide bars. However, with warp knitting, a huge variety of knit structures can be produced. Indeed, no other technology can match warp knitting technology in the production of net structures. Thus, with the right stitch construction and proper material selection, it is possible to knit square, rectangular, rhomboidal, hexagonal or almost round shape [6].

Symmetrical nets are produced when two identically-threaded guide bars overlap in balanced lapping movements in opposition. The threaded guides of an incomplete arrangement in each bar should pass through the same needle space at the first link in order to overlap adjacent needles otherwise both may overlap the same needle and leave the other without a thread.

For example, the knitted fabric structure shown in Figure 2 is formed from two different yarns using a partial, $|\cdot| \cdot \mid \cdot$, drawing-in of guide bar. To produce such knits the same combinations of stitches are

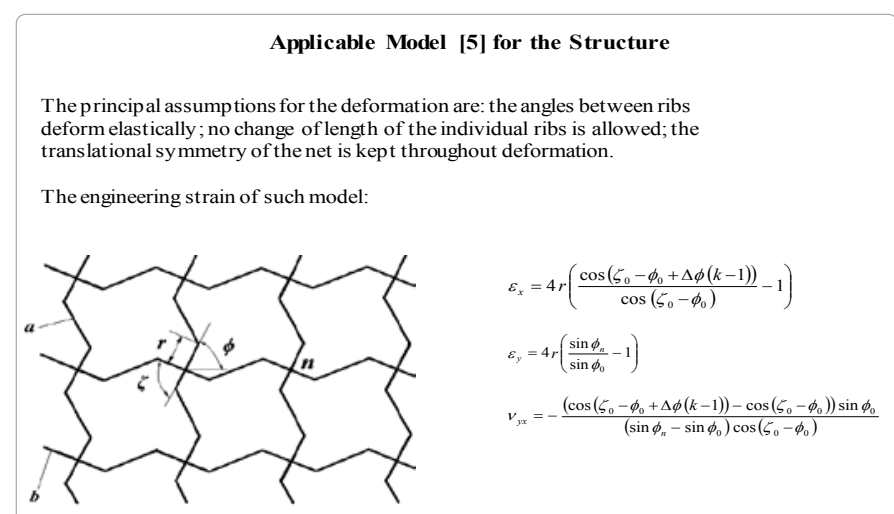

Figure 1: Schematic of geometrical model for the Structure.

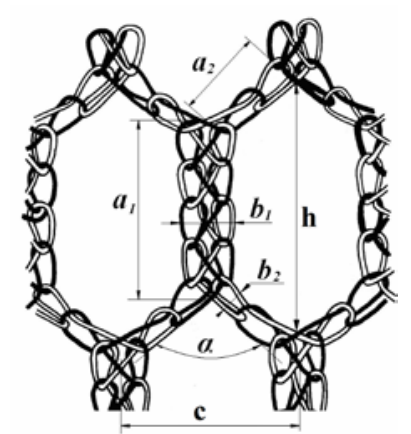

Figure 2: Knitted fabric structure.

used, though in one case the coupled wales of tricot-tricot stitches are formed on different needles. After knitting and allowing some fabric relaxation under standard conditions, the warp knit structures form hexagonal nets. A typical net consists of vertical ribs $a b$ and de from tricot courses of length $h$ and diagonal ribs $b c, c d$, ef and fa from chain courses of length $l$. The diagonal rib is disposed at an angle $a$ to the horizontal. The net's size primarily depends on the knitting machine gauge and linear density of yarn. But the rib's lengths $h$ and $l$ depend on the number of courses in each part of the repeating unit.

It is possible to create the honeycomb fabrics with different net sizes on the same machine by changing the knitting parameters. In this convectional structure, the wale moves past one another during fabric deformation in the wale direction causing the warp knit fabric and its varying size between vertical ribs $a b$ and $d e$ within the net to decrease. The fabric width will also decrease. Hence, it is necessary to change the disposition of the ribs in the net in order to form a functional auxetic knit structure (Figure 3) [7]. During stretch deformation in wale direction of this fabric the distance between point $c$ and $f$ increases. The diagonal ribs $b c, c d$, ef and $f a$ move to the horizontal disposition, which is perpendicular to the stretch direction. In this mode, the angle $\alpha$ is approaching to $0^{\circ}$ and the distance between vertical ribs $a b$ and $d e$ increases. Figure 3 is an illustration of the auxetic ability of such a structure.

To achieve this auxetic property, it is required to employ a high elastic yarn in the basic structure. This yarn must be placed between the stitch wale in the knitting direction to insure that the fabric structure 
Citation: Ugbolue SC, Kim YK, Warner SB, Fan Q, Yang CL, et al. (2012) Engineered Warp Knit Auxetic Fabrics. J Textile Sci Engg 2:e103. doi:10.4172/2165-8064.1000e103

Page 3 of 8

will retain necessary configuration after relaxation.

The filling yarn is laid between neighboring wales and wraps the junctures of the ground loops as shown in inlay Type A (Figure 4a) or between the guide bar as shown in Type B (Figure 4b). In order to study the influence of in-lay yarn position both types of structure were produced. Also minimum of five or six guide bars are needed to produce such knit structure.

The schematic geometrical model of the auxetic textile structure is shown in Figure $1[5,12]$. The in-lay warp knit is the preferred structure used to create such an auxetic textile structure. It is feasible to use two types of filling yarns: $a$ - vertical (warp) and $b$ - horizontal (weft), in such structure. But several difficulties are encountered when producing knit structures with long weft filling yarn on warp knitting machine. Therefore, we configured the knit structures in which the in-lay yarns are used to effect compound repeating units. In these structures we utilized the chain as a basic structure and employed only two guide bars to produce such knit auxetic fabrics (Figure 5). The first guide bar which forms the base loops has a full drawing-in and the second guide bar which forms the inlay structure has an incomplete drawing-in. For better contact of two in-laying yarns in point $n$ (Figure 2) and to facilitate the creation of the carcass from in-lay yarns, we incorporated a design that allowed the formation of loops from in-lay yarns in the same courses (Figure 6).

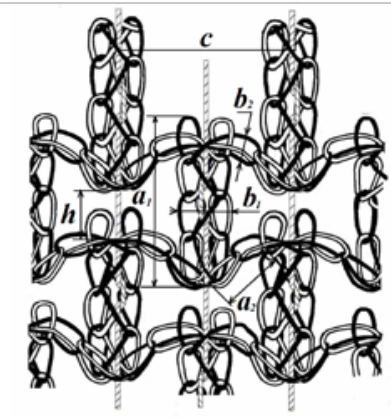

Figure 3: Functional auxetic knit structure.

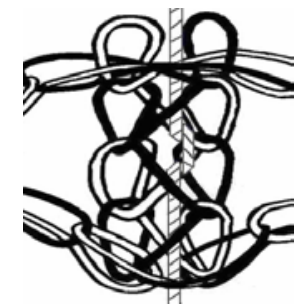

Figure 4a: Inlay Type A.

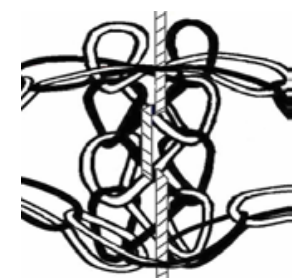

Figure 4b: Inlay Type B.

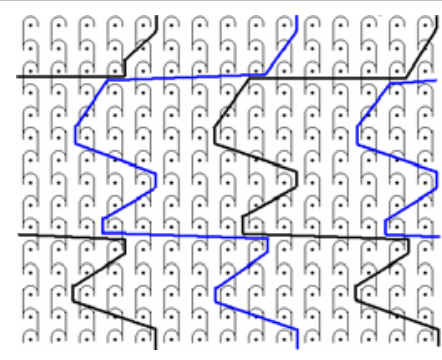

Figure 5: Lapping movements of two guide bars.

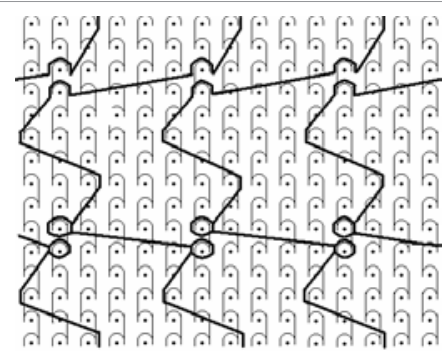

Figure 6: Lapping movement showing the creation of carcass.

\section{Experimental}

\section{Materials}

For detailed study of auxetic knit structures from non-auxetic yarns, some types of fillet warp knit fabrics and some types of in-lay warp knit fabrics were designed and produced. These fabrics were made on a 10 gauge crochet knitting machine with one needle bed. The fillet warp knit fabrics were made from 2 ends ground yarn of 250 denier polyester yarn manufactured by Du Pont. 150 denier polyester yarn covered with I end of 40 denier Spandex supplied by Unifi Inc. was used as a high elastic in-laying component. Nine types of warp knit fabrics were produced with different number of tricot courses $(3,5$ or 7) and different number of chain courses (from 1 to 3 ).

The polyester wrapped with Spandex yarn used in this study is supplied by Unifi Inc. and made up of 96 filaments polyester yarn which is wrapped with Spandex. The linear density of polyester is 150den, while that of Spandex is 40den.

\section{Warp knitting process}

Muller Crochet Knitting machine (RD3MT3/630) used in this study is a 10 gauge machine, 630 millimeter wide and equipped with 8 guide bars but only 4 guide bars are used in this study. For this study, the auxetic structures each having 7 tricot course numbers and different chain course numbers, namely 1,2 , and 3 chain course numbers, were designated 7X-1B, 7X-2B and 7X-3B respectively.

\section{Measurement of yarn properties}

Two yarns used in this study, namely, $100 \%$ polyester and polyester filament yarn covered with Spandex, were tested according to ASTM D 2256 Standard Test Method for Tensile Properties of Yarns by the Single-Strand Method.

Using a gauge length of $25.4 \mathrm{~cm}$ and crosshead speed of $10.16 \mathrm{~cm} /$ min the polyester yarn was tested on the Instron tensile testing machine 
and a tenacity of $1.454 \mathrm{gf} / \mathrm{den}$ was obtained. Similarly, the tenacity of the polyester yarn wrapped with Spandex was determined as $0.415 \mathrm{gf} /$ den using a gauge length of $5.08 \mathrm{~cm}$ and crosshead speed of $30.48 \mathrm{~cm} /$ min. on an Instron tensile testing machine.

\section{Measurement of fabric properties}

Loop length: Loop length is the fundamental unit of weft knitted structure. It influences fabric dimensions and other properties including weight. However, in warp knitting it is the length of yarn knitted into each structural unit that is given a lot of prominence.

The loop length of $10 \mathrm{~cm}$ of Bar \#1, \#3, \#5 and \#6 are tested respectively during the knitting process. The loop numbers were calculated in $\mathrm{mm} / 100 \mathrm{~cm}$.

Courses per unit length \& wales per unit length: A course is a predominantly horizontal row of loops produced by adjacent needles during the same knitting cycle. In warp knitting each loop in a course normally composed of a separate yarn. Courses per inch (cpi) or courses per $\mathrm{cm}$ are used to evaluate the loops along the axial or walewise direction.

A wale is a predominantly vertical column of needle loops produced by the same needle knitting at successive knitting cycles and thus intermeshing each new loop through the previous loop. In warp knitting a wale can be produced from the same yarn. Wales per inch (wpi) or wales per $\mathrm{cm}$ are used to evaluate the loops along the transverse or coursewise direction.

The number of courses and wales per unit length are obtained by using a counting glass. The results are reported using SI units namely, number of courses or wales in $100 \mathrm{~mm}$. The mean of ten readings is recorded for each direction of the fabric.

Stitch $\operatorname{density}(\mathbf{S})$ : The term loop or stitch density $S$ is the total number of needle loops in a square area measurement. It is obtained by multiplying, for instance, the number of courses and wales, per square unit length together. The unit is loops $/ \mathrm{in}^{2}$ or loops per $\mathrm{cm}^{2}$.

Thickness and basis weight: The thickness (with the unit of $\mathrm{mm}$ ) of each sample is tested using a Thickness Testing Instrument according to ASTM D1777-64 [7].

Each sample was also weighed on an electronic balance to determine its basis weight.

Measurement of tensile properties: Video-extensometry along with micro-tensile testing techniques were employed by using Instron 5569 Mechanical Tester ASTM D5034-95(2001) for determining the breaking strength and elongation of textile fabrics (Grab Test). To check for specimen slippage, the specimen was marked across at the front inner edge of each jaw. It is noted that the mark will move away from the jaw edge if slippage occurred. The result was discarded and another sample taken if the specimen slipped in the jaws broke at the edge of or in the jaws, or the test results fell markedly below the average for the set of specimens.

Instrument control (including standard and customizable methods) and data collection and analysis were performed using the Instron software.

\section{Measurement of poisson's ratio}

All samples were tested by straining the entire fabric strip evenly and the sample was measured to obtain the Poisson's ratio by using the equation,

$$
V_{x y}=-\frac{\varepsilon_{x}}{\varepsilon_{y}}
$$

where $\varepsilon_{\mathrm{x}}$ is the strain in the $\mathrm{x}$-direction, or transverse strain, and $\varepsilon_{\mathrm{y}}$ is the strain in the $y$-direction, or the axial strain. All samples were initially three inches, or $7.62 \mathrm{~cm}$, and strained at a rate of $2 \mathrm{in} / \mathrm{min}$ or $5.08 \mathrm{~cm} /$ $\mathrm{min}$, in the walewise direction.

For straining in the coursewise direction the gauge length was 1 inch or $2.54 \mathrm{~cm}$ and the strain rate was $1 \mathrm{in} / \mathrm{min}$ or $2.54 \mathrm{~cm} / \mathrm{min}$. The test process was observed with a Sensicam QE camera. The strain of the sample was measured using the camera to capture an image of the sample at different strain rates, totaling 55 pictures per sample. The width of each sample was measured in three locations to insure that the measured Poisson's ratio was as accurate of measurement as possible. Each fabric structure was tested three times, using different samples of the fabric structure to obtain accurate measurements of the Poisson's ratio. All samples were strained using an Instron 5569 tensile testing machine. The Poisson's ratio was obtained after all samples had been photographed and using Photoshop software. Again the dimensions of the fabric were measured in pixels and the change was calculated using excel software. For the Poisson's ratio measurement a reference length was not needed, as it is only the ratio of the changes in dimension that are meaningful, so the units of length are arbitrary, so long as they are kept constant. The diagram in Figure 7 shows the setup used to determine the Poisson's ratio for all samples.

\section{Results and Discussion}

\section{Dimensional and structural properties}

Production data for the different types of fillet warp knitted fabric

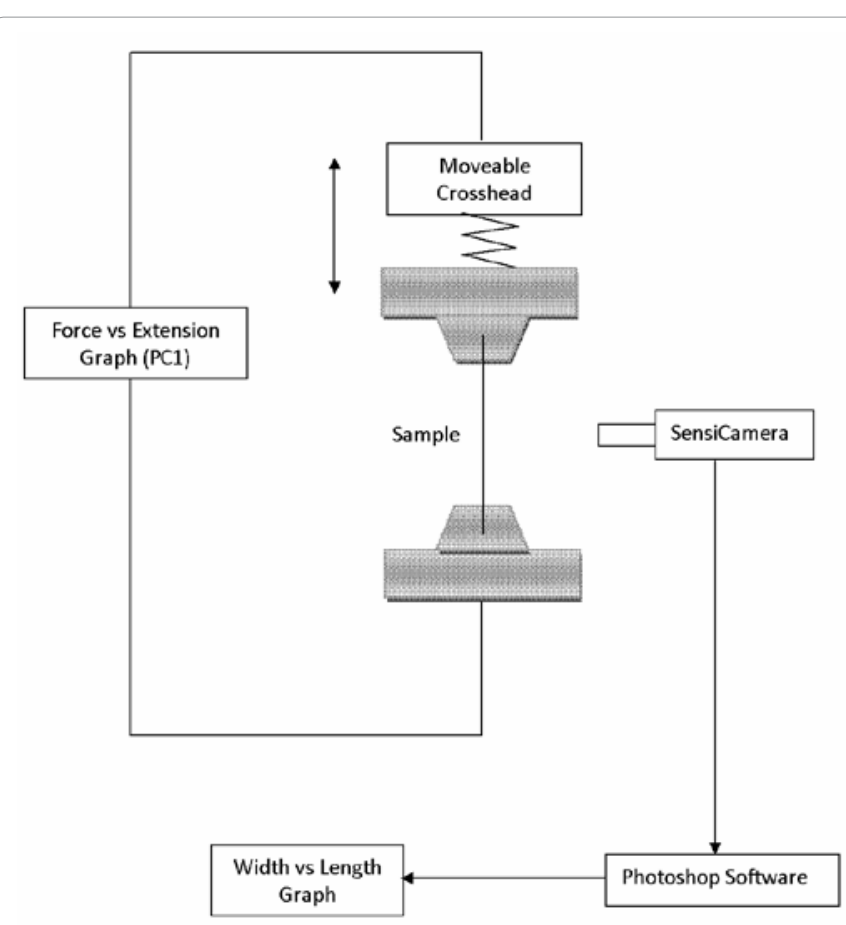

Figure 7: The setup used to determine the Poisson's ratio for all samples. 
are given in Table 1. The structural parameters of control and auxetic warp knit fabrics are shown in Table 2.

Correlated analyses highlighted dependences between parameters of the knitted structure. The number of wales per unit length depends on number of chain courses; the stitch density depends on number of courses per unit length; the thickness depends on the stitch density and number of courses per length; and finally, the basis weight depends on the thickness, the stitch density and number of courses per unit length. However, these structural parameters do not fully describe the auxetic properties of the fabrics. It is noted that the auxetic properties depend on the interaction of vertical and horizontal ribs in the knitted structure. Thus, a method was developed for quantifying the geometrical structural unit cell of the auxetic structure based on measured parameters, namely, $a_{1}, a_{2}, h$ and $c$ (shown in Figure 2). We have, therefore, devoted a major part of our work to analyzing the geometric characteristics of the unit cell, as given in Table 3.

Correlated analyses confirm dependences between basis weight
(Figure 4), stitch density (Figure 5) and intrinsic unit size displacement, $\left(h-a_{1}\right) / c$. Also, Figure 6 shows dependence between intrinsic unit size displacement, $\left(h-a_{1}\right) / c$. and number of chain courses at repeat. It is noted that the $\left(h-a_{1}\right) / c$, ratio is constant for the control samples and does not depend on drawing-off force. For the auxetic structure, the $\left(h-a_{1}\right) / c$ ratio increases with corresponding increase in the number of chain courses at repeat. However, no dependence is observed between the intrinsic unit size displacement, $\left(h-a_{1}\right) / c$. and drawing-off force for the auxetic structure.

\section{Analysis of poison's ratio}

The measure of the Poisson's ratio is a main characteristic of the auxetic ability of materials. The conventional materials have positive Poisson's ratio whereas auxetic materials have negative Poisson's ratio. Ugbolue et al. [21,22] have discussed in detail the behavior of warp knit auxetic structures fabricated with non-auxetic filaments. In this study the Poisson's ratio results of all the samples for the non-auxetic structure (no inlay yarn) are shown in Table 4.

\begin{tabular}{|c|c|c|c|c|c|}
\hline $\begin{array}{c}\text { Sample } \\
\text { Designation }\end{array}$ & Type of Structure & $\begin{array}{c}\text { Number of tricot } \\
\text { courses }\end{array}$ & $\begin{array}{c}\text { Number of chain } \\
\text { courses }\end{array}$ & Type of inlaying & Gear Disposition \\
\hline $7 C-1-24 / 34$ & conventional & 7 & 1 & - & $24 / 34$ \\
\hline $7 C-2-24 / 34$ & conventional & 7 & 2 & - & $24 / 34$ \\
\hline $7 C-3-24 / 34$ & conventional & 7 & 3 & - & $24 / 34$ \\
\hline $7 X-1 A-24 / 34$ & auxetic & 7 & 1 & $A$ & $24 / 34$ \\
\hline $7 X-2 A-24 / 34$ & auxetic & 7 & 2 & A & $24 / 34$ \\
\hline $7 X-3 A-24 / 34$ & auxetic & 7 & 3 & A & $24 / 34$ \\
\hline $7 X-1 B-24 / 34$ & auxetic & 7 & 1 & B & $24 / 34$ \\
\hline $7 X-2 B-24 / 34$ & auxetic & 7 & 2 & B & $24 / 34$ \\
\hline $7 X-3 B-24 / 34$ & auxetic & 7 & 3 & $\mathrm{~B}$ & $24 / 34$ \\
\hline $7 C-1-24 / 36$ & conventional & 7 & 1 & - & $24 / 36$ \\
\hline $7 C-2-24 / 36$ & conventional & 7 & 2 & - & $24 / 36$ \\
\hline $7 C-3-24 / 36$ & conventional & 7 & 3 & - & $24 / 36$ \\
\hline $7 X-1 A-24 / 36$ & auxetic & 7 & 1 & $A$ & $24 / 36$ \\
\hline $7 X-2 A-24 / 36$ & auxetic & 7 & 2 & $A$ & $24 / 36$ \\
\hline $7 X-3 A-24 / 36$ & auxetic & 7 & 3 & A & $24 / 36$ \\
\hline
\end{tabular}

Table 1: Production data for the different types of fillet warp knitted fabric.

\begin{tabular}{|c|c|c|c|c|c|c|c|c|c|c|c|}
\hline \multirow{2}{*}{$\begin{array}{c}\text { Sample } \\
\text { Designation }\end{array}$} & \multicolumn{2}{|c|}{ Number of courses $\mathrm{N}_{\mathrm{c}}$} & \multicolumn{2}{|c|}{$\begin{array}{l}\text { Number of } \\
\text { wales, } N_{w}\end{array}$} & \multicolumn{2}{|c|}{ Stitch density, S } & \multirow{2}{*}{$\begin{array}{c}\text { Fabric } \\
\text { Thick-ness } \\
\text { t, mm }\end{array}$} & \multirow{2}{*}{$\begin{array}{l}\text { Basis weight } \\
\text { of fabric, } \mathrm{g} / \mathrm{m}^{2}\end{array}$} & \multirow{2}{*}{$\begin{array}{l}\text { Run-in of } \\
\text { ground yarn, } \\
\text { Rg, mm }\end{array}$} & \multirow{2}{*}{$\begin{array}{c}\text { Run-in of } \\
\text { in-lay yarn, } \\
\text { Ri, mm }\end{array}$} & \multirow{2}{*}{$\begin{array}{c}\text { Run-in ratio, } \\
r=\mathrm{Ri} / \mathrm{Rg}\end{array}$} \\
\hline & per inch & per $\mathrm{cm}$ & per inch & per $\mathrm{cm}$ & $\begin{array}{l}\text { per square } \\
\text { inch }\end{array}$ & $\begin{array}{l}\text { per sq. } \\
\mathrm{cm}\end{array}$ & & & & & \\
\hline $7 C-1-24 / 34$ & 27.3 & 10.7 & 11.5 & 4.5 & 313.5 & 48.6 & 0.74 & 134.59 & 2424.9 & - & - \\
\hline $7 C-2-24 / 34$ & 28.3 & 11.1 & 8.9 & 3.5 & 251.8 & 39.0 & 0.71 & 130.69 & 2364.6 & - & - \\
\hline 7C-3-24/34 & 29.9 & 11.8 & 7.6 & 3.0 & 226.4 & 35.1 & 0.70 & 102.87 & 2299.2 & - & - \\
\hline $7 X-1 A-24 / 34$ & 45.4 & 17.9 & 9.3 & 3.7 & 422.7 & 65.5 & 1.09 & 215.33 & 2412.0 & 593.1 & 0.246 \\
\hline $7 X-2 A-24 / 34$ & 47.5 & 18.7 & 8.0 & 3.1 & 380.0 & 58.9 & 1.01 & 191.12 & 2277.3 & 607.4 & 0.267 \\
\hline $7 X-3 A-24 / 34$ & 51.8 & 20.4 & 6.5 & 2.6 & 336.0 & 52.1 & 0.99 & 169.03 & 2485.3 & 625.9 & 0.252 \\
\hline $7 \mathrm{X}-1 \mathrm{~B}-24 / 34$ & 43.8 & 17.2 & 11.3 & 4.4 & 438.0 & 67.9 & 1.02 & 215.45 & 2454.0 & 634.6 & 0.259 \\
\hline $7 X-2 B-24 / 34$ & 51.2 & 20.2 & 9,5 & 3.7 & 475.6 & 73.7 & 0.99 & 241.49 & 2410.9 & 627.2 & 0.260 \\
\hline $7 X-3 B-24 / 34$ & 55.8 & 22.0 & 7.7 & 3.0 & 491.8 & 76.2 & 1.03 & 230.55 & 2334.0 & 634.6 & 0.272 \\
\hline $7 C-1-24 / 36$ & 28.4 & 11.2 & 11.3 & 4.4 & 331.8 & 51.4 & 0.77 & 153.87 & 2357.7 & - & - \\
\hline $7 C-2-24 / 36$ & 29.7 & 11.7 & 9.5 & 3.7 & 282.0 & 43.7 & 0.76 & 140.42 & 2248.8 & - & - \\
\hline 7C-3-24/36 & 30.1 & 11.9 & 7,7 & 3.0 & 231.0 & 35.8 & 0.74 & 115.94 & 2215.2 & - & - \\
\hline $7 X-1 A-24 / 36$ & 43.9 & 17.3 & 9.6 & 3.8 & 421.9 & 65.4 & 1.07 & 199.21 & 2454.0 & 582.6 & 0.237 \\
\hline $7 X-2 A-24 / 36$ & 45.9 & 18.1 & 8.0 & 3.1 & 367.2 & 56.9 & 1.02 & 187.39 & 2411.4 & 579.1 & 0.240 \\
\hline $7 X-3 A-24 / 36$ & 49.6 & 19.5 & 6.9 & 2.7 & 342.4 & 53.1 & 1.03 & 181.30 & 2404.0 & 594.5 & 0.247 \\
\hline
\end{tabular}

Table 2: The structural parameters of control and auxetic warp knit fabrics. 
Citation: Ugbolue SC, Kim YK, Warner SB, Fan Q, Yang CL, et al. (2012) Engineered Warp Knit Auxetic Fabrics. J Textile Sci Engg 2:e103. doi:10.4172/2165-8064.1000e103

Page 6 of 8

\begin{tabular}{|c|c|c|c|c|c|c|c|c|}
\hline $\begin{array}{c}\text { Sample } \\
\text { Designation }\end{array}$ & $\begin{array}{c}\text { Length of } \\
\text { vertical rib, } \\
\mathrm{a}_{1}, \mathrm{~mm}\end{array}$ & $\begin{array}{l}\text { Length of } \\
\text { diagonal rib, } \\
\mathrm{a}_{2}, \mathrm{~mm}\end{array}$ & $\begin{array}{c}\text { Width of vertical } \\
\text { rib, } \\
b_{1}, \mathrm{~mm}\end{array}$ & $\begin{array}{c}\text { Width of } \\
\text { diagonal rib, } \\
\mathrm{b}_{2}, \mathrm{~mm}\end{array}$ & $\begin{array}{c}\text { Distance } \\
\text { between two } \\
\text { units in vertical } \\
\text { plane, } \\
\text { h, mm }\end{array}$ & $\begin{array}{c}\text { Distance } \\
\text { between two } \\
\text { units in horizontal } \\
\text { plane, } \mathrm{c}, \mathrm{mm}\end{array}$ & $\begin{array}{l}\text { Measured unit } \\
\text { size ratio } h / a_{1}\end{array}$ & $\begin{array}{c}\text { Intrinsic unit size } \\
\text { displace-ment } \\
\text { (tangent), }\left(\mathrm{h}-\mathrm{a}_{1}\right) / \mathrm{c}\end{array}$ \\
\hline $7 C-1-24 / 34$ & 7.72 & 2.01 & 1.54 & 1.08 & 9.02 & 4.83 & 1.168 & 0.269 \\
\hline $7 C-2-24 / 34$ & 6.82 & 2.44 & 1.39 & 1.11 & 8.95 & 5.66 & 1.312 & 0.377 \\
\hline 7C-3-24/34 & 6.97 & 3.02 & 1.46 & 1.04 & 10.56 & 6.52 & 1.515 & 0.550 \\
\hline $7 X-1 A-24 / 34$ & 4.98 & 2.50 & 1.61 & 1.05 & 3.25 & 5,04 & 0.653 & -0.343 \\
\hline $7 X-2 A-24 / 34$ & 5.13 & 3.18 & 1.56 & 0.97 & 3.96 & 6.46 & 0.772 & -0.181 \\
\hline $7 X-3 A-24 / 34$ & 5.11 & 3.53 & 1.56 & 0.85 & 4.06 & 7.10 & 0.795 & -0.147 \\
\hline $7 X-1 B-24 / 34$ & 5.17 & 2.63 & 1.53 & 0.85 & 4.20 & 5.27 & 0.814 & -0.183 \\
\hline $7 X-2 B-24 / 34$ & 5.18 & 2.04 & 1.56 & 0.92 & 3.49 & 5.60 & 0.674 & -0.301 \\
\hline $7 C-1-24 / 36$ & 7.30 & 1.84 & 1.48 & 1.10 & 8.53 & 4.62 & 1.168 & 0.265 \\
\hline $7 C-2-24 / 36$ & 6.59 & 2.59 & 1.49 & 1.02 & 9.57 & 6.38 & 1.452 & 0.468 \\
\hline 7C-3-24/36 & 6.51 & 2.87 & 1.38 & 1.01 & 10.09 & 6.09 & 1.550 & 0.588 \\
\hline $7 X-1 A-24 / 36$ & 4.43 & 2.52 & 1.56 & 0.81 & 3.46 & 5.03 & 0.781 & -0.192 \\
\hline $7 X-2 A-24 / 36$ & 4.84 & 3.18 & 1.55 & 0.94 & 3.80 & 6.23 & 0.785 & -0.167 \\
\hline $7 X-3 A-24 / 36$ & 5.09 & 3.43 & 1.50 & 0.85 & 4.11 & 6.70 & 0.807 & -0.146 \\
\hline
\end{tabular}

Table 3: Analysis of the geometric characteristics of unit cell.

Furthermore, the measurement of Poisson's ratio is an important tool for determining the auxetic property of materials. If the Poisson's ratio is negative then the structure is auxetic. The Poisson's ratio results of the samples in the walewise direction for structure with Type A inlaying are shown in Figure12. From the plot, it is obvious that all the samples showed auxetic property at the first stage of elongation (5-10 $\%)$. But there is no observed dependence between the Poisson's ratio and drawing-off force.

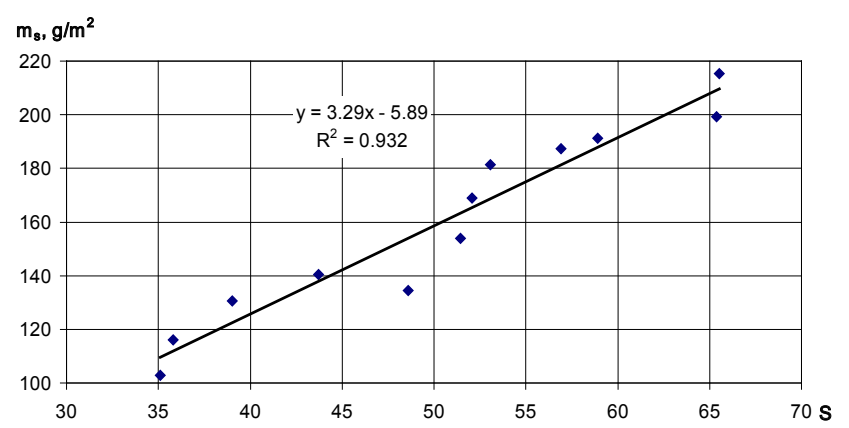

Figure 8: Relation between Basis weight, $\mathrm{ms}$ and Stitch density for various auxetic warp knit structures.

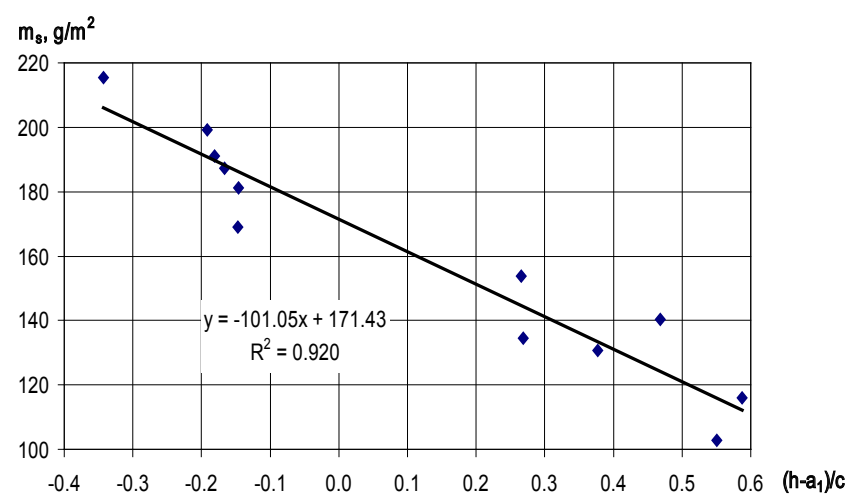

Figure 9: Relation between Basis weight, $\mathrm{ms}$ and Intrinsic unit size displacement $\left(\mathrm{h}-\mathrm{a}_{1}\right) / \mathrm{c}$.

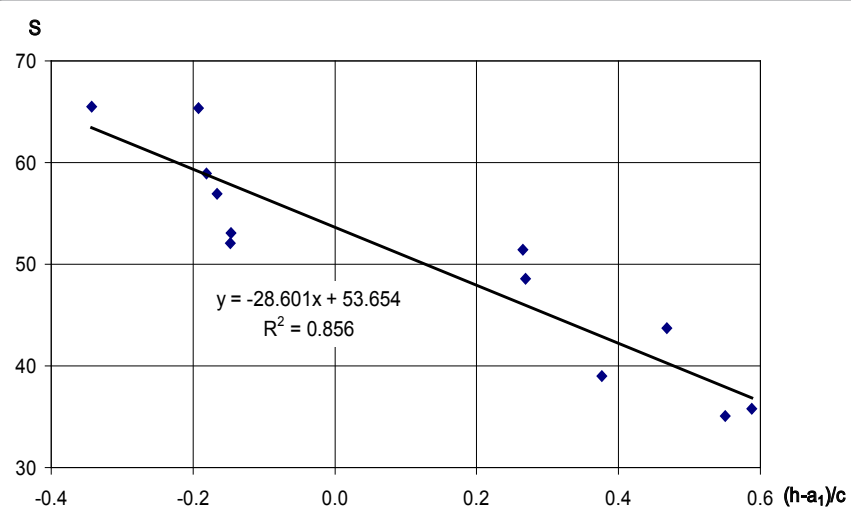

Figure 10: Relation between stitch density, $\mathrm{S}$, and Intrinsic unit size displacement, $\left(\mathrm{h}-\mathrm{a}_{1}\right) / \mathrm{c}$.

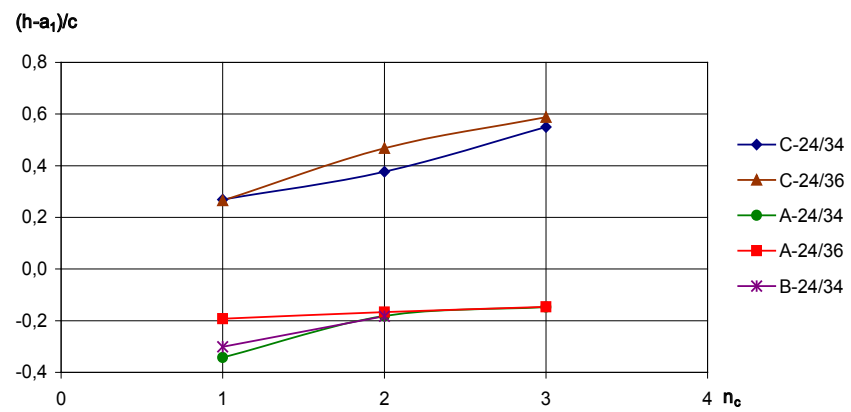

Figure 11: Relation between Intrinsic unit size displacement, $\left(h-a_{1}\right) / c$ and number of chain courses.

In order to study the influence of various inlaying types on the Poisson's ratio, both structures A and B were tested in two directions. The results are plotted in Figure 13 (walewise direction) and Figure14 (coursewise direction). An examination of Figures 13 and 14 shows that the B Structure with 3 chain courses at repeat, has the smallest Poisson's ratio along the walewise and coursewise directions. The factor which influences the Poisson's ratio is identified as intrinsic unit size displacement, which depends on chain course numbers. This effect is 
Citation: Ugbolue SC, Kim YK, Warner SB, Fan Q, Yang CL, et al. (2012) Engineered Warp Knit Auxetic Fabrics. J Textile Sci Engg 2:e103. doi:10.4172/2165-8064.1000e103

Page 7 of 8

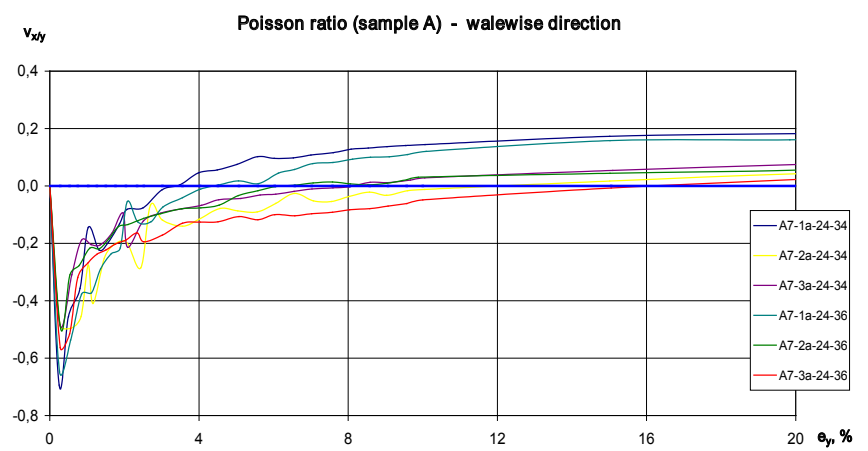

Figure 12: Relation between Poisson's ration and strain $\%$ in the walewise direction for Type A auxetics at different gear configurations.

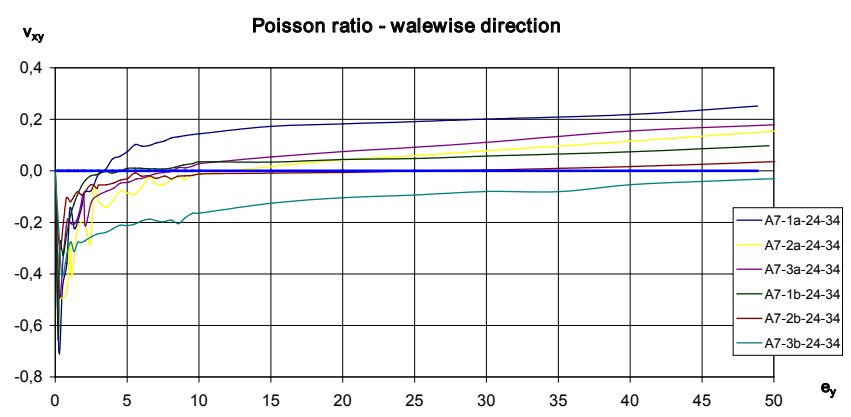

Figure 13: Relation between Poisson's ratio and strain \% in the walewise direction.

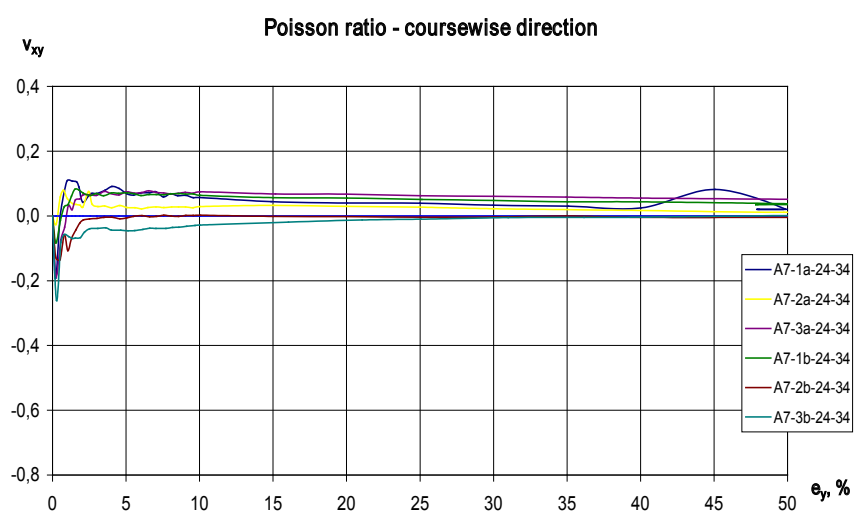

Figure 14: Relation between Poisson's ratio and strain \% in the coursewise direction

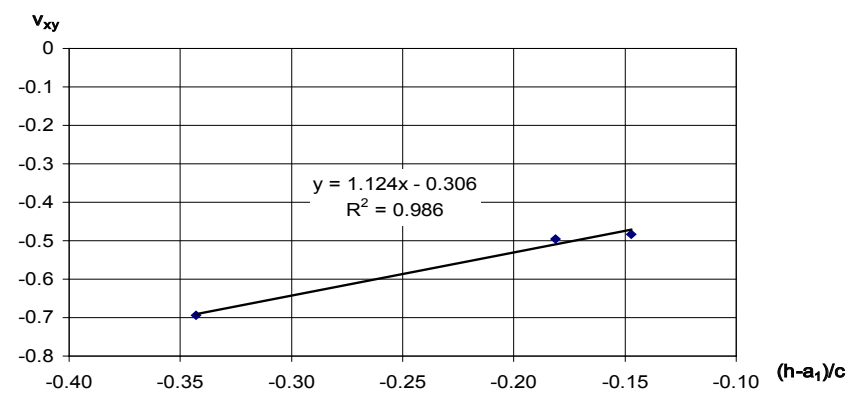

Figure 15: Relation between Poisson's ratio and Intrinsic unit size displacement, $\left(\mathrm{h}-\mathrm{a}_{1}\right) / \mathrm{c}$.

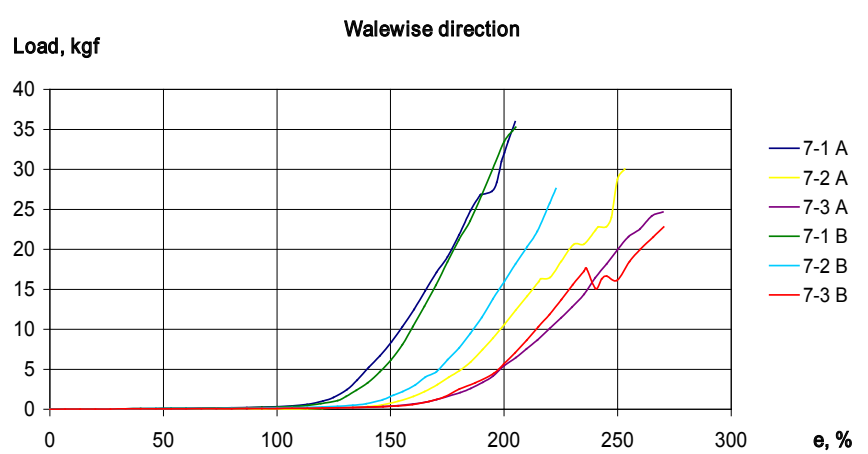

Figure 16: Load-extension plots for Auxetic structures in the walewise direction.

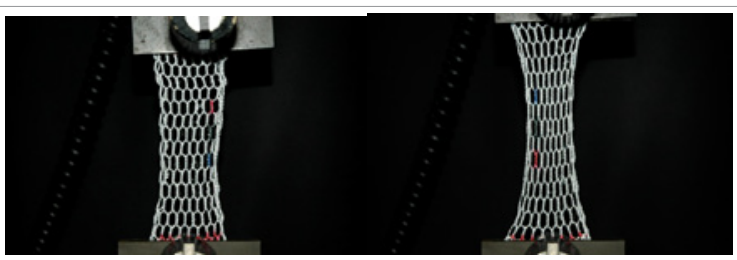

Figure 17: Conventional (non-auxetic) Conventional (non-auxetic) 7C-1A-24-34 at onset of Poisson's 7C-1A-24-34 at the end of Poisson's test ( $0 \%$ strain) in the walewise direction test ( $50 \%$ strain) in the walewise direction.

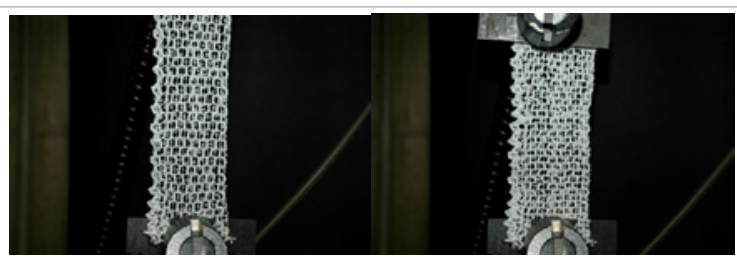

Figure 18: Auexetic 7-1A-24-34 at onset of Poisson's Auexetic 7-1A-24-34 at the end of Poisson's test ( $0 \%$ strain) in the walewise direction test (50\% strain) in the walewise direction.

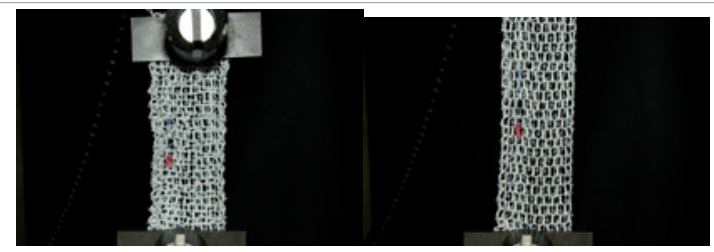

Figure 19: Auexetic 7-1B-24-34 at onset of Poisson's Auexetic 7-1B-24-34 at the end of Poisson's test ( $0 \%$ strain) in the walewise direction test ( $50 \%$ strain) in the walewise direction.

\begin{tabular}{|c|c|}
\hline Strain \% & Poisson's Ratio \\
\hline 1.38 & 0.54 \\
\hline 13.77 & 0.57 \\
\hline 27.54 & 0.57 \\
\hline 41.311 & 0.55 \\
\hline 55.08 & 0.54 \\
\hline
\end{tabular}

Table 4: Poisson's ratio test results for non-auxetic structure 7C-1 Walewise.

shown in Figure15 based on the analyzed data using the SPSS software. It is surmised that the Poisson's ratio values decrease as the number of tricot courses increase. This is due to the fact that larger tricot courses lead to longer $a_{1}$ (length of vertical rib) values. Thus, unit sizes with larger $a_{1}$ can become wider during stretching. 
Citation: Ugbolue SC, Kim YK, Warner SB, Fan Q, Yang CL, et al. (2012) Engineered Warp Knit Auxetic Fabrics. J Textile Sci Engg 2:e103. doi:10.4172/2165-8064.1000e103

Page 8 of 8

\section{Conclusion}

It is evident that the samples designed and knitted in this study exhibit auxetic property. Negative Poisson's ratio is observed at small loading during the tensile testing. It is noted that the auxetic properties depend on the interaction of vertical and horizontal ribs in the knitted structure. Thus, a method was developed for quantifying the geometrical structural unit cell of the auxetic structure based on measured parameters, namely, $\mathrm{a}_{1}, \mathrm{a}_{2}, \mathrm{~h}$ and $\mathrm{c}$. It is also noted that the strain values increase with corresponding increase in the Poisson's ratio. The factor which influences the negative Poisson's ratio is identified as intrinsic unit size displacement, $\left(\mathrm{h}-\mathrm{a}_{1}\right) / \mathrm{c}$, which depends on chain course numbers.

\section{Acknowledgement}

The authors are grateful for the funds received from the National Textile Center under the US Department of Commerce Grant 02-07400 in support of this research.

\section{References}

1. Andy Alderson, Kim Alderson (2005) Expanding materials and applications: exploiting auxetic textiles. Technical Textiles International 777: 29-34.

2. Ravirala N, Alderson K, Davies P, Simkins V, Alderson A (2006) Negative Poisson's ratio polyester fibers. Textile Research Journal 76: 540-546.

3. Philip J McMullan, Satish Kumar, Anselm C Griffin (2006)Textile Fibers Engineered from Molecular Auxetic Polymers.Project M04-GT21 National Textile Center Annual Report 1-10.

4. Mouritz A, Bannister M, Falson P, Leong K (1999) Review of applications for advanced three dimensional fibre textile composites. Composites Part:Applied Science and Manufacturing 30: 1445-1461.

5. Smith C, Grima J, Evans K (2000) A novel mechanism for generating auxetic behaviour in reticulated foam: Missing rib foam model. Acta Materiala 48: 43494356.

6. Leong K, Ramakrishna S, Huang Z, Bibo G (2000) The potential of knitting for engineering composites. Composites Part A 31: 197-220.

7. Gommers B, Verpoest I, Van Houtte P (1998) Analysis of knitted fabric reinforced composites: Part I Fibre orientation distribution. Composites. Part Applied Science and Manufacturing 29: 1579-1588.

8. Hu H, Wang Z, Liu S (2011) Development of auxetic fabrics using flat knitting technology. Textile Research Journal 81: 1493-1502.

9. Hook, P and Evans K (2006) Auxetix site.

10. Venkatraj R (1996) Net Fabrics. The Indian Textile Journal 46-51.

11. Whitty JPM , Alderson A, Myler P, Kandola B (2003)Towards the design of sandwich panel composites with enhanced mechanical and thermal properties by variation of the in-plane Poisson's ratios. Composites. Part: Applied Science and Manufacturing 34: 525-534.

12. Gaspar N, Ren XJ, Smith CW, Grima JN, Evans KE (2005) Novel honeycombs with auxeti behavior. Acta Materiala 53: 2439-2445.

13. Grima JN, Gatt R (2005) Empirical modelling using dummy atoms EMUDA an alternative approach for studying auxetic structures. Molecular Simulation 31 915-924.

14. Alderson KL, Webber RS, Evans KE (2007) Microstructural evolution in the processing of auxetic microporous polymers. Physica Status Solidi B: Basic Solid State Physics 244: 828-841.

15. Alderson KL, Pickles AP, Evans KE (1994) Auxetic Polyethylene: The effect of a negative Poisson's ratio on hardness. Acta Metall Mater 42: 2261-2266.

16. Webber RS, Alderson KL, Evans KE (2008) A novel fabrication route for auxetic polyethylene, part 2: mechanical properties. Polymer Engineering and Science 48: $1351-1358$.

17. Simkins VR, Ravirala N, Davies PJ, Alderson A, Alderson KL (2008) An experimental study of thermal post-production processing of auxetic polypropylene fibres. Physica Status Solidi B: Basic Solid State Physics 245: 598-605.

18. Alderson A, Alderson KL (2007) Auxetic materials. J Aerospace Engineering 221: 565-575.

19. Ugbolue SC, Warner S B, Kim YK, Fan Q, Yang, et al. (2006) The Formation and Performance of Auxetic Textiles, (NTC Project F06-MD09) , annual report, Pennsylvania, National Textile Center.

20. Ugbolue SC, Warner SB, Kim YK, Fan Q, Yang CL, et al. (2007) The Formation and Performance of Auxetic Textiles. (NTC ProjectF06-MD09), annual report, Pennsylvania, National Textile Center.

21. Ugbolue SC, Warner SB, Kim YK, Fan Q, Yang CL, et al. (2010) The Formation and Performance of Auxetic Textiles Part 1: Theoretical and Technical Considerations. J Text Inst 101: 660-667.

22. Ugbolue SC, Warner S B, Kim YK, Fan Q, Yang CL, et al. (2011) The Formation and Performance of Auxetic Textiles Part 1I: Geometry and Structura Properties. J Text Inst 102: 424-433.

23. Alderson A, Alderson K L (2005) Expanding materials and applications: exploiting auxetic textiles. Tech Text Int 14: 29-34.

24. Ugbolue SC, Warner S B, Kim YK, Fan Q, Yang CL, et al. (2008)The Formation and Performance of Auxetic Textiles. (NTC Project F06-MD09), annual report, Pennsylvania, National Textile Center.

25. Ugbolue SC, Warner S B, Kim YK, Fan Q, Yang CL, et al. (2009)The Formation and Performance of Auxetic Textiles. (NTC Project F06MD09), annual report, Pennsylvania, National Textile Center.

26. Ugbolue SC, Warner SB, Kim YK, Fan Q, Yang CL, et al. ( 2009) Auxetic Fabric Structures and Related Fabrication Methods. World Patent No. 002479 A1. 